GEFAD / GUJGEF41(2): 1203-1225(2021)

\title{
Ortaokul Öğrencilerinin Okuma Alışkanlığı ve Problem Çözme Becerisinin İncelenmesi*
}

\author{
Analysis of Middle-School Students' Reading and \\ Problem-Solving Abilities
}

\author{
Sevim SEVGi ${ }^{1}$, Mustafa KARAKAYA ${ }^{2}$ \\ ${ }^{1}$ Erciyes Üniversitesi, Eğitim Fakültesi, Matematik ve Fen Bilimleri Eğitimi Bölümü, \\ Ilköğretim Matematik Öğretmenliği. sevimsevgi@erciyes.edu.tr \\ ${ }^{2}$ Erciyes Üniversitesi, Eğitim Bilimleri Enstitüsü, Matematik ve Fen Bilimleri Eğitimi \\ Anabilim Dal, İlköğretim Matematik Öğretmenliği Bilim Dalı. \\ mustafakarakaya008@gmail.com
}

Makalenin Geliş Tarihi: 07.12.2020

Yayına Kabul Tarihi: 09.04.2021

$\ddot{O} Z$

Bu araştırmanın amacı ortaokul ögrencilerinin okuma allşkanllkları düzeyi ile problem çözme becerileri arasindaki iliş̧kileri incelemektir. Araştırma İ̧̧ Anadolu Bölgesi'ndeki bir ildeki ortaokulda 5, 6, 7 ve 8. sinfflarda öğrenim gören toplam 1595 ortaokul ögrrencisi ile yürütülmüsstür. Veri toplama aracı Tok, Küçük ve Kırmacı (2015) tarafindan gelişstirilen ortaokul kitap okuma alışkanlı̆̆ ölçeği ile Serin ve Saygıll (2010) tarafindan geliştirilen ilköğretim düzeyindeki çocuklar için problem çözme envanteri (ÇPÇE) kullanllmıştır. Araştırma nicel araştırma yöntemlerinden tarama modeline uygun olarak gelişstirilmiştir. Betimsel istatistik, Mann-Whitney $U$, korelasyon analizi ve Kruskal Wallis testi yapılmıştır. Bu araşstrma için ortaokul öğrencilerinin kitap okuma alıskkanlı̆̆ ölçeği Cronbach Alpha değeri 0,863 olarak, ilköğretim düzeyindeki çocuklar için problem çözme envanteri (ÇPÇE) Cronbach Alfa güvenirlik katsaylsı 0,555 olarak bulunmuştur. Araştrma sonucunda ortaokula devam eden kiz ve erkek ögrrencilerin okuma alışkanllkları ve problem çözme becerilerinin ortalamaları arasında istatistiksel olarak anlaml farkllık bulunmamaktadır. Ortaokul öğrencilerinin kitap okuma alışkanlığı ve problem çözme becerisi arasinda pozitif yönlü bir ilişki olduğu bulunmuştur. Sinıf seviyelerinde okuma alışkanlığı ve problem çözme becerisi ortalamaları istatistiksel olarak anlamlı düzeyde bir fark oluşturmaktadir.

Anahtar Sözcükler: Okuma alışkanlı̆̆l, Problem çözme, Ortaokul ögrencisi

\footnotetext{
* Alıntılama: Sevgi, S. ve Karakaya, M. (2021). Ortaokul Öğrencilerinin Okuma Alışkanlığı ve Problem Çözme Becerisinin İncelenmesi. Gazi Üniversitesi Gazi Eğitim Fakültesi Dergisi, 41(2), 1203-1225.
} 


\section{ABSTRACT}

This study aims to examine the relationships between middle-school students' reading ability and their problem-solving skills. The research was carried out with 1595 middle-school students studying in $5^{\text {th }}, 6^{\text {th }}, 7^{\text {th }}$, and $8^{\text {th }}$ grades in a middle school in a Central Anatolia Region province. The data collection tools were middle-school reading ability scale developed by Tok, Küçük, and Kirmact (2015), and the problem-solving inventory (PSI) for elementary school children developed by Serin and Saygll (2010). The research model was survey model, one of the quantitative research methods. Descriptive statistics, the Mann-Whitney $U$ test, correlational analysis, and Kruskal Wallis analysis were used. The Cronbach Alpha value of the middle-school reading ability scale was found to be 0.863. The Cronbach Alpha reliability coefficient for the problem-solving inventory (PSI) for elementary school children was found to be 0.555. As a result of the study, there was no statistically significant mean difference between female and male middle-school students' problem-solving abilities and reading abilities. There was a positive relationship between middle-school students reading ability and problem-solving skills. Reading abilities and problem-solving abilities differed according to grade levels.

Keywords: Reading ability, Problem-solving, Middle-school student 


\section{GíRiş}

İnsanlık tarihinin en büyük kazanımlarından biri hiç şüphesiz alfabe ve yazının keşfedilmesidir. $\mathrm{Bu}$ başarıyı kuşkusuz okuma ve öğrenme becerilerinin kazanılması takip etmektedir (Samuels \& Farstrup, 2006). İnsanlar okuma sayesinde yeni sözcükler öğrenir, yeni düşünceler kazanır, yeni hayaller kurmayı öğrenir ve yaratıcıllklarını geliştirerek ufuklarının genişlemesini ve derinleşmesini sağlarlar (Akyol, 2018). Okuma ve anlama insanın kendini sürekli geliştirme ihtiyacının doğal bir sonucudur. Okuma, belli baş̧ı bilgi edinme yollarından biri olması yönüyle, kişilere hayatları boyunca devam edecek olan öğrenme süreçlerinin kapılarını açmaktadır. Öğrenme, büyük oranda okumayla gerçekleşir. Okuma alışkanlığı olmayan ve okuduğunu anlayamayan öğrencilerin derslerinde başarılı olmaları, kelime dağarcıklarını geliştirmeleri, yeni tecrübeler kazanmaları beklenemez (Ünalan, 2006). Öğretim hayatının neredeyse tamamında okuma yardımıyla bilgiye ulaşılmakta ve öğretim hamleleri bu temel üzerine inşa edilmektedir. $\mathrm{Bu}$ yönüyle, okuma alışkanlığ kişiye yaşamı boyunca kullanacağı öğrenme kaynaklarının kapılarını aralamaktadır. Okuma alışkanlığının edinilmesi, birçok entelektüel maharetin de aktif kullanımını sağlamaktadır.

\section{Okuma Alışkanlığı}

Okuma, temel anlamda yazıyı oluşturan sembollerin ve harflerin seslendirilmesi şeklinde tanımlanmaktadır. Fakat okuma becerisi temeldeki yazı ve harfleri tanımanın çok ötesinde, daha karmaşı zihinsel faaliyetler içermektedir. Okuma sürecinin karmaşıklığı yapılan farklı tanımlamalardan da anlaşılmaktadır. Okuma, "Bir yazıyı, sözcükleri, cümleleri, noktalama işaretleri ve öteki öğeleriyle görme, algılama ve kavrama sürecidir." (Kavcar \& Oğuzkan, 1998; s.41). Güneş (2017) okumay1, "Görme, algılama, seslendirme, anlama, beyinde yapılandırma gibi göz, ses ve beynin çeşitli işlevlerinden oluşan karmaşık bir süreç" (s. 117) olarak tanımlamıştır. Okuma, "Gözlerin ve ses organlarının çeşitli hareketlerini ve zihnin yazılı sembolleri anlamasıyla oluşur." şeklinde tanımlanmıştır (Demirel, 2007, s. 117). Okuma "Ön bilgilerin kullanıldığı, yazar ve okuyucu arasındaki etkili iletişime dayalı, uygun bir 
yöntem ve amaç doğrultusunda, düzenli bir ortamda gerçekleştirilen anlam kurma sürecidir." (Akyol, 2018, s. 1).

Tanımlamaların hepsinde okumada sadece sembol ve harfleri seslendirmekten ziyade anlama vurgu yapan ifadeler yer almaktadır. Okumanın asıl amac1, yazılı metni verildiği şekilde anlama ve hızlı bir şekilde kavramaktır. Göz ile algılanan ifadelerin başta beyinde algılanması, tanınması ve sonrasında da hatırlanarak anlamlandırılması gerekmektedir. Okuduğunu kavrayan kişi en somut haliyle okuduğu metin üzerinde analiz ve sentez yapabilmelidir. Okuyucu okunan metindeki parçalar arasında anlam bütünlüğü kurabilmelidir. Anlama; "Görülenlerden, duyulanlardan, okunanlardan veya bir kelimeden, sözden, davranıştan, olay ve olgudan bir sonuç çıkarma, mesaj alma, ne demek istendiğini veya neye işaret ettiğini kavrama ve bilgi edinmedir." (Karakuş, 2005, s. 91). Bu yönüyle okuma ve dinleme becerilerinin amacı anlamaktır. Kısacası okuma, okuduğunu tam ve doğru biçimde anlama sürecidir.

Temel öğretimde okuma becerisi kazanımının ötesinde, temel dil becerilerinin kullanımının geliştirilmesine ve bu beceri alanlarından biri olan okumanın bir alışkanlık hâline dönüştürülmesi de önemlidir (Marshall, 1994). Öğrenenlere temel okuma becerisinin ötesinde okuma zevki ve okuma alışkanlığı kazandırılmalıdır. Alışkanlık, "Canlı bir varlığın tekrarlanan bir etkiyle edindiği tutum veya öğrenme sonucu otomatik olarak yapılan davranıştır." (Güney, 1998, s.10) olarak tanımlanmaktadır. Sürekli tekrarlarla kişi okumaya alıştırılmalıdır. Okumayı alışkanlık hâline getirmiş bireylerde temel düzeyde okuduğunu anlama becerisinin gelişmiş olduğu görülür (Dreher, 2002). Daha ileri düzeyde okuma alışkanlığı, olaylara ve hayata daha geniş perspektiflerden bakabilme kabiliyeti ile düşünme ve değerlendirme alışkanlığı da kazandırır (Karatay, 2014). Okumaya ayrılan zamanın artması, yani okuma alışkanlığının gelişmesi, okuduğunu anlama başarısını da olumlu yönde etkilemektedir (Guthrie \& Wigfield, 1999). Okul dışında gerçekleştirilen boş zaman okumaları, başta okuduğunu anlama olmak üzere kelime bilgisi, konuşma becerisi ve bilişsel gelişimi de olumlu yönde etkilemektedir (Hughes \& Rodge, 2007). 


\section{Problemi Anlama ve Problem Çözme}

Matematik, bilimde olduğu kadar hayatın içerisinde karşılaş̧ı̆̆ımız sorunları çözmek için kullandığımız bir araçtır. Öğrenenler varlıklarını sürdürmek, kapasitelerini artırmak, yaşam standartlarını yükseltmek için okuma, yazma, sayısal işlem yapma ve problem çözme gibi temel öğrenme ihtiyaçlarına gereksinim duyarlar (Baykul \& Fidan, 1994). Matematik, bu ihtiyaçların karşılanabilmesi için elde edilmesi gereken kabiliyetlerin bir kısmını oluşturan sayısal işlem, problem çözme ve akıl yürütme gibi bilişsel becerilerin kazanılmasına yardımcı olur. Matematik kendine özgü bir alfabesi olan, sembol ve şekilleri içeren, bilinen, bilinmeyen ifadeler için harfler kullanan, kendine has sözcükleri ve cümleleri kapsayan, özel ve genel bir dildir (Umay, 2002). Ulusal Matematik Öğretmenleri Konseyi (National Council of Teachers of Mathematics-NCTM) matematik öğrenmenin temel gerekçelerinden biri olarak problem çözmeyi ifade etmektedir (NTCM, 1988). Problem çözme yeni matematiksel fikirler ortaya koymak ve yetenekleri ortaya çıkarmak için önemli bir araçtır.

Problem çözme, ilk olarak Polya tarafından basamaklar hâlinde tanımlanmıştır. Polya'nın (2017) problem çözme ile ilgili sunduğu model dört adımdan oluşmaktadır. Bu adımlar şunlardır: 1. Problemi anlama, 2. Çözüme yönelik plan oluşturma, 3. Planı uygulama, 4. Kontrol etme. Problemi anlama aşamasında öğrenci problemi anlamalı ve istekli olmalıdır. Problemin yazılı ifadesi her şeyden önce anlaşılır olmalıdır. Problemle karşılaşan öğrencinin öncelikle problemi tekrar ifade etmesi ve bunu seri bir biçimde yapması gerekir. Öğrenci ayrıca problemin temel unsuru olan bilinmeyeni, verilenleri, istenenleri varsa başka koşulları da belirlemelidir. Bunun yanında problem içerisinde yer alan ifade biçimine göre bir sembol seçmeli veya bağlantı kurma açısından bir şekil çizmeli, şekil üzerinden bu bağı göstermelidir. Kişinin problemi çözerken anlama aşamasında problemi mümkün olduğunca açık bir biçimde zihninde canlandırması gerekmektedir. Kişi ancak bu şekilde problemi zihnine sokabilir ve hafızasını harekete geçirebilir.

Problemin çözümü, problemin ana hatlarını değerlendirmeyle başlamalıdır. Önceki öğrenilenler yardımıyla bu kısımlara açıklık getirilmeli ve bu kısımlar net bir şekilde 
idrak edilmelidir. Hafızamız bize cevap verdiğinde problemin çözümüne başlanmalıdır. Problem çeşitli yönlerden ele alınmalı, problemin farklı kısımları üzerinde durulmalıdır. Ayrıntılara inilmeli ve ayrıntılar farklı yönlerden incelenmeli, ayrıntıların farklı alternatifleri oluşturulmalıdır. Probleme bu farklılıklar üzerinden yaklaşılmalıdır. Problemin çözümü için bildik, tanıdık ve görülen yerden çözüme başlanmalıdır. Önceki öğrenilenlerle ilişki kurulmaya çalışılmalıdır. Geçmiş yaşantılarınızda benzer bir problemle karşılaşılıp karşılaşılmadığı hatırlanmalıdır. İncelenen problem cümlesinde tanıdık gelen kısımlar görülmeli ve işe yarar kısımlar kavranmaya çalışılmalıdır. Probleme bu şekilde yaklaşıldığında çözüme götürecek bilgilere ulaşılabilir veya problemin çözümüne yardımcı olacak bir fikir kavranabilir. Fark edilen bu fikirler problemin çözümü için nasıl ilerleneceği hakkında problemi çözen kişiye yol gösterir. Fark edilen fikirler genelde eksiksizdir ve kişiyi problemin çözümüne kavuşturur. Fakat problemi çözen kişi eksik veya yanlış bir fikir edinmişse problemin çözümü için mevcut fikrini, problemin durumu üzerinde tekrar ele almalıdır. Yapılan bu tekrarlar problemi çözen kişiye önceden edinilen bilgilerle bağlantı kurma imkânı sağlar. Bu sayede problemi çözen kişi eksik fikirleri üzerinden başka yeni fikir edinebilir, problemin çözümü için bir yol bulabilir. Belki de bu fikirler bizi yanlış çözüm yollarına götürecektir ama bu fikirler problem çözen kişiyi daha tutarlı ve dengeli bir kavrama noktasına ulaştırır (Polya, 2017).

Akıcı okuma becerisine sahip olmayan öğrenciler, yavaş yavaş, kelime kelime, kesik kesik okuma yapmanın yanında, tonlama, duraklama ve vurgulara uygun olmayan bir biçimde okuma yapmaktadır (Güneş, 2007). Bu şekilde icra edilen okumalarda öğrenciler dikkatlerini kelime seslendirmeye ve tanımaya vermektedir. $\mathrm{Bu}$ durum öğrencilerin çok sayıda hata yapmalarına ve sözcük tanıma problemi yaşamalarına neden olmaktadır (Yılmaz, 2008). Akıcı okumanın matematik problemlerinin çözümünde öğrenci başarısını artıracağı düşünülmektedir.

$\mathrm{Bu}$ çalışmanın amacı, ortaokul öğrencilerinin okuma alışkanlığı ve problem çözme becerilerini farklı değişkenler açısından incelemektir. Bu amaçla aşağıda belirtilen araştırma sorularına cevap aranacaktır. 
1) Ortaokula devam eden kız ve erkek öğrencilerin okuma alışkanlıkları ve problem çözme becerilerinin ortalamaları arasında anlamlı düzeyde bir fark oluşturmakta mıdır?

2) Ortaokul öğrencilerinin okuma alışkanlıkları ve problem çözme becerileri arasında anlamlı bir var mıdır?

3) Ortaokul öğrencilerinin okuma alışkanlığı ve problem çözme becerisi ortalamaları, sınıf seviyeleri yönünden anlamlı düzeyde bir fark oluşturmakta mıdır? 


\section{YÖNTEM}

$\mathrm{Bu}$ araştırma nicel verilerin kullanıldığ bir tarama araştırmasıdır. Bir topluluğun belirli özelliklerini tespit etmek için bilgi toplanmasını amaçlayan çalışmalara tarama araştırması denilmektedir (Büyüköztürk, Çakmak, Akgün \& Demirel, 2016). Bu tarz araştırmalar genel olarak büyük toplulukların (yaş, cinsiyet, öğrenim durumu, medeni hal, görme kusuru, gelir düzeyi vb.) araştırmaya konu özelliklerini belirlemek amacıyla yapılan betimsel araştırmalardır (Büyüköztürk, 2007; Can, 2016). Tarama çalışmaları kişilerin kendilerinin belirlediği inançları veya davranışlarla ilgili bilgi toplamak için uygundur. Farklı ortaokul öğrenci gruplarının, benzer ya da farklı yönleri hakkında en ideal bilgi toplama yöntemi tarama modelleridir (Robson, 2017) Tarama modellerinde elde edilen sonuçlar, belli bir yapıyı açıklamamıza yardımcı olarak bizi betimsel yorumlamaya götürür. Elde edilen veriler doğrultusunda ortaokul öğrencilerinin okuma alışkanlığı ve problem çözme becerilerinin türlü yönlerden incelenmesi amaçlanmıştır.

\section{Araştırmanın Örneklemi}

$\mathrm{Bu}$ araştırmada seçkisiz örnekleme yaklaşımlarından biri olan amaçsal örnekleme kullanılmıştır. Amaçsal örnekleme çalışmanın amacına bağlı olarak veri açısından zengin durumların seçilerek etraflıca araştırma yapılması olarak tanımlanır (Büyüköztürk, Çakmak, Akgün \& Demirel, 2016). Örneklem, Orta Anadolu'da bulunan bir ilin merkez ilçesinde yer alan bir örgün eğitim kurumunda öğrenim gören 779'ü kız $(\% 48,8)$ 816'sı erkek $(\% 51,2)$ ortaokul öğrencisinden oluşmaktadır. Tablo 1'de cinsiyete göre öğrenci dağılımı verilmiştir. Tablo 1'e göre örneklemin cinsiyet yönünden dengeli bir dağılım gösterdiği söylenebilir.

Tablo 1. Cinsiyete Göre Öğrenci Dağılımı

\begin{tabular}{lll}
\hline Cinsiyet & $\mathrm{f}$ & $\%$ \\
\hline Erkek & 816 & 51,2 \\
K1z & 779 & 48,8 \\
Toplam & 1595 & 100 \\
\hline
\end{tabular}




\section{Veri Toplama Araçları}

\section{Ortaokul Kitap Okuma Alışkanlığı Ölçeği (OKOAÖ)}

Kitap okuma alışkanlıklarını tespit etmek için Tok, Küçük ve Kırmacı (2015) tarafından geliştirilen Ortaokul Kitap Okuma Alışkanlığı Ölçeği (OKOAÖ) kullanılmıştır. Cronbach Alpha değeri 0,863 olarak bulunmuştur. Ölçek 15 maddeden oluşmuş olup 5'li Likert tipi sorular içermektedir. Cevap seçenekleri "1. Kesinlikle katılmıyorum, 2. Katılmiyorum, 3. Kısmen kat1liyorum, 4. Katılıyorum, 5. Tamamen katıliyorum" şeklindedir.

\section{İlköğretim Düzeyindeki Çocuklar İçin Problem Çözme Envanteri (ÇPÇE)}

Problem çözme becerileri için Serin, Serin ve Saygılı (2010) tarafindan geliştirilen ilköğretim düzeyindeki çocuklar için problem çözme envanteri (ÇPÇE) kullanılmıştır. Cronbach Alfa güvenirlik katsayısının 0,80 olduğu saptanmıştır. Ölçek 5'li Likert tipi 24 maddeden oluşmaktadır. Cevap seçenekleri "1. Asla, 2. Nadiren, 3. Bazen, 4. Sık Sık, 5. Her Zaman" şeklindedir. ÇPÇE için güvenilirlik analizinde problem çözme güvenilirlik istatistik değerleri, problem çözme envanteri için 0,555 değerini almıştır. Nakip ve Yaraş'a (2016) göre ölçeğin Cronbach Alpha güvenirlik katsayısının \%25’ten fazla olması istenilir. İlköğretim düzeyindeki çocuklar için problem çözme envanteri ise düşük derecede güvenilir aralığında yer almaktadır.

\section{Etik Kurallara Uygunluk}

$\mathrm{Bu}$ araştırmanın veri toplama sürecine gönüllü olan adaylar katılmışlardır. Araştırma sonuçlarının sadece amaç kapsamında kullanılacağı belirtilmiştir. Araştırmada elde edilen veriler herhangi bir değişiklik yapılmadan etik kurallara uygun olarak verilmiştir. Ayrıca, etik kurul onay belgesi Ek 1'de gösterilmektedir.

\section{Veri Analizi}

Ortaokul kitap okuma alışkanlığı ölçeği (OKOAÖ) ve problem çözme envanterinden (ÇPÇE) toplanan verilerin analizi SPSS 25 ile yapılmıştır. Bu kapsamda, betimsel 
istatistik, normallik analizi, Mann-Whitney U Testi, korelasyon analizi ve KruskalWallis Testi yapılmıştır.

\section{BULGULAR}

$\mathrm{Bu}$ bölümde araştırmanın sorularının yanıtları için çocuklar için ortaokul kitap okuma alışkanlığı ölçeği (OKOAÖ) ve çocuklar için problem çözme envanterinden (ÇPÇE) toplanmış verilere yapılan analizlere ve elde edilen bulgulara yer verilmiştir.

Kitap okuma alışkanlık ölçeği ve çocuklar için problem çözme envanterinden elde edilen verilerin betimsel istatistiklerine bakılmıştır. Tablo 2'de ortaokul öğrencilerinin kitap okuma alışkanlığı ölçeği (OKOAÖ) ve problem çözme envanterinden (ÇPÇE) elde edilen betimsel istatistik değerlerinden ortalama, medyan ve merkezi eğilim ölçüleri verilmiştir. Tablo 2'de verilen betimsel istatistik incelendiğinde problem çözme ve okuma alışkanlığı değerlerine ilişkin ortalama, medyan ve tepe değerlerinin birbirine yakın olduğu görülmektedir.

Tablo 2. Ölçeklerin Betimsel İstatistik Değerleri

\begin{tabular}{lllllll}
\hline Ölçek Puanları & $\mathrm{n}$ & $\bar{X}$ & Medyan & Mod & Çarpıklık & Basıklık \\
\hline Problem Çözme & 1595 & 71,5524 & 71 & 68 & 0,192 & 0,726 \\
Okuma Alışkanlığı 1595 & 53,9818 & 55 & 57 & $-0,552$ & 0,279 \\
\hline
\end{tabular}

Tablo 2'de betimsel istatistik değerleri incelendiği basıklık ve çarpıklık değerleri görülmektedir. Bursal (2017) örneklem sayısının 30 ve üzeri olduğu araştırmalarda Kolmogorov-Smirnov test sonucuna bakılması gerektiğini örneklem sayısının 30'un altında olduğu zaman Shapiro-Wilks testinin sonucuna bakılması gerektiğini önermektedir. Kolmogorov-Smirnov testi sonucu D $(1595)=0,052 ; p=0,000<0,05$ okuma alışkanlığı ve problem çözme anketinde D (1595) $=0,046 ; p=0,000<0,05$ değişkenlerinin veri dağılımı 0,05 anlamlılık düzeylerinde normal dağılım sağlamamaktadır. 


\section{Cinsiyete Göre Okuma Alışkanlığı ve Problem Çözme Becerilerinin İncelenmesi}

Araştırmada ortaokula devam eden kız ve erkek öğrencilerin okuma alışkanlığg ortalamalarının ve problem çözme becerilerinin ortalamaları arasında istatistiksel olarak anlamlı bir fark olup olmadığı incelenmiştir. Tablo 3'te Kolmogorov-Smirnov testi sonucu cinsiyete göre normal dağılım sergilememektedir. Problem çözme envanteri erkek öğrenciler için $\mathrm{D}(1595)=0,53 ; \mathrm{p}=0,000<0,05, \mathrm{k} 1 \mathrm{z}$ öğrenciler için $\mathrm{D}(1595)=$ 0,$49 ; p=0,000<0,05$ değerini almaktadır. Okuma alışkanlığ ölçeği erkek öğrenciler için $\mathrm{D}(1595)=0,42 ; \mathrm{p}=0,000<0,05, \mathrm{k1z}$ öğrenciler için $\mathrm{D}(1595)=0,062 ; \mathrm{p}=0,000<0,05$ değerini almaktadır. Kız ve erkek öğrencilerin veri dağılımı 0,05 anlamlılık düzeylerinde normal dağılım sağlamamaktadır.

Tablo 3. Problem Çözme ve Okuma Alışkanlığı Ölçeklerinin Cinsiyete Göre Normallik Test Sonucu

\begin{tabular}{lllll}
\hline & & & Serbestlik & $\mathrm{p}$ \\
Ölçek & Cinsiyet & İstatistik & Derecesi & \\
\hline Problem Çözme & Erkek & 0,53 & 816 & 0,000 \\
& Kiz & 0,49 & 779 & 0,000 \\
Okuma Alışkanlığı & Erkek & 0,42 & 816 & 0,020 \\
& Kiz & 0,62 & 779 & 0,000 \\
\hline
\end{tabular}

Cinsiyete göre problem çözme becerilerinin ortalama puanları ve okuma alışkanlıkları ortalama puanları arasında anlamlı bir fark olup olmadığının 0,05 anlamlılık düzeyinde parametrik olmayan testlerden Mann-Whitney U Testi analiz sonuçları verilmiştir. Problem çözme becerisi Mann-Whitney $U=316278$; $z=-0,169$; $p=0,866$; Wilcoxon $\mathrm{W}=620088$ olup, problem çözme becerisi yönünden k1z ve erkek öğrencilerin ortalamaları arasında istatistiksel olarak anlamlı bir fark yoktur. Okuma alışkanlığı Mann-Whitney $U=248039 ; \mathrm{z}=-7,594$; Wilcoxon $\mathrm{W}=581375 ; \mathrm{p}=0,000$ değerlerini almıştır. Tablo 4'te okuma alışkanlığının cinsiyete göre oluşan istatiksel anlamlı farkın k1z öğrenciler lehine olduğu görülmektedir.

Tablo 4. Okuma Alışkanlığının Cinsiyete Göre İncelenmesi

\begin{tabular}{llll}
\hline Cinsiyet & $\mathrm{n}$ & Ortalama Sirası & Siralamalar Toplamı \\
\hline Erkek & 816 & 712,47 & 581375 \\
Kiz & 779 & 887,59 & 691435 \\
\hline
\end{tabular}


Tablo 4'te okuma alışkanlığının cinsiyete göre oluşan istatiksel anlamlı farkın kız öğrenciler lehine olduğu görülmektedir.

\section{Okuma Alışkanlığı ve Problem Çözme Becerileri Arasındaki İlişkinin İncelenmesi}

Ortaokula devam eden öğrencilerin problem çözme becerileri ve okuma alışkanlıkları ortalamaları arasındaki ilişkiyi incelemek amacıyla korelasyon analizi yapılmıştır. Veriler normal dağılım göstermediğinden Spearman's rho korelasyon analizi yapılmıştır. Problem çözme becerisi ve okuma alışkanlığı arasında 0,01 düzeyinde anlamlıdır $(\mathrm{r}=0,124 ; \mathrm{p}=0,000<0,01)$. Öğrencilerin okuma alışkanlıkları ile problem çözme becerileri arasında pozitif yönlü anlamlı bir ilişkisi olduğu görülmektedir (Cohen $\&$ Cohen, 1983).

\section{Sınıf Seviyesine Göre Okuma Alışkanlığı ve Problem Çözme Becerilerinin İncelenmesi}

Okuma alışkanlığ 1 ve problem çözme becerilerinin ortalama puanlarının sınıf seviyelerine göre anlamlı biçimde farklı olup olmadığını yorumlanmak gerekir. Bu amaçla sınıf seviyelerinde grup ortalamalarının her birinin normal dağılım sergileyip sergilemediğini öğrenmek için Kolmogorov-Smirnov normallik testi uygulamıştır. Bu araşıırma için anlamlılık düzeyini 0,05 olarak belirlemiştir. Tablo 5 'te sınıf düzeylerinin normallik test sonuçları verilmiştir. Problem çözme ve okuma alışkanlığı KolmogorovSmirnov normallik testi sonuçları $\mathrm{p}<0,05$ olduğu için bağımlı değişken puanları hiçbir alt grupta normal dağılım varsayımını sağlamamaktadır.

Tablo 5. Problem Çözme ve Okuma Alışkanlığı Ölçeklerinin Sınıf Seviyesine Göre Normallik Test Sonucu

\begin{tabular}{lllll}
\hline Ölçek & Sınıf & İstatistik & Serbestlik Derecesi & $\mathrm{p}$ \\
\hline Problem Çözme & 5 & 0,069 & 250 & 0,006 \\
& 6 & 0,047 & 492 & 0,011 \\
& 7 & 0,052 & 356 & 0,020 \\
& 8 & 0,064 & 497 & 0,000 \\
\hline Okuma Alışkanlığı & 5 & 0,095 & 250 & 0,000 \\
& 6 & 0,058 & 492 & 0,001 \\
& 7 & 0,042 & 356 & $0,200^{*}$ \\
& 8 & 0,053 & 497 & 0,002 \\
\hline
\end{tabular}


Tablo 6'da gruplar arası farkl11ıklara göre ortaokula devam eden öğrencilerin okuma alışkanlığı toplam puanlarının gruplar arası ortalamaları sınıf seviyeleri düzeyinde anlamlı bir fark vardır $\left[\mathrm{X}^{2}(3,1595)=102,789 ; \mathrm{p}=0,000<0,05\right]$. Benzer şekilde, ortaokula devam eden öğrencilerin problem çözme becerileri toplam puanları gruplar arasında ortalamaları sinıf seviyeleri düzeyinde $\left[\mathrm{X}^{2}(3,1595)=12,643 ; \mathrm{p}=0,000<0,05\right]$ anlamlı bir fark vardır. Dört sınıf düzeyinin en az ikisi arasında anlamlı bir fark olduğu görülmektedir. Ortaokulda öğrenime devam eden öğrencilerin hangi sınıf seviyeleri arasında fark olduğunu anlamak için çoklu karşılaştırma testi yapılmıştır.

Tablo 6. Okuma Alışkanlığı ve Problem Çözme Kruskal-Wallis Testi

\begin{tabular}{lllll}
\hline Ölçek & $\mathrm{n}$ & $\boldsymbol{X}^{2}$ & Serbestlik derecesi & $\mathrm{p}$ \\
\hline Okuma Alıškanlığı 1 & 1595 & 102,789 & 3 & 0,000 \\
Problem Çözme & 1595 & 12,643 & 3 & 0,000 \\
\hline
\end{tabular}

Okuma alışkanlığı ve problem çözme puanlarının hangi alt gruplar arasında farklılaştığının tespiti için parametrik olmayan testlerden iki bağımsız örneklemi karşılaştırmada kullanılan Mann-Whitney $U$ testi kullanılmıştır. Tablo 7'de test sonuçları verilmiştir. Kruskal Wallis $\mathrm{H}$ testi sonrası yapılacak ikili karşılaştırma testlerinde toplam hatanın \%5'i aşmaması için Bonferroni Düzeltmesi (Bonferroni Adjustment) yapılması tavsiye edilir (Pallant, 2016). Düzeltilmiş Anlamlılık Düzeyi: 0,05 / (Yapılacak ikili Karşılaşırma Testi Sayısı) şeklinde tanımlanmıştır (Bursal, 2017). Dört alt grubun birbiri ile karşılaşacağı bir durumda yapılacak Bonferroni Düzeltmesi sonrası ikili karşılaştırma testlerinde esas alınacak anlamlılık düzeyi 0,05/4=0,0125 olacaktır. Tablo 7'de sınıf düzeyleri ortalamaları arasındaki fark incelendiğinde beşinci sınıf düzeyinde okumakta olan öğrencilerin problem çözme becerileri yönünden altınc1 sınıf düzeyinde Mann-Whitney $U=51311,5 ; z=-3,694 ; p$ $=0,000<0,0125$ olduğu için ortalama puanlar arasında altıncı sınıf lehine anlamlı bir fark vardır. Beşinci sınıf düzeyinde okumakta olan öğrencilerin problem çözme becerileri yönünden yedinci sınıf düzeyinde Mann-Whitney $U=35006,5 ; z=-4,478 ; p$ $=0,000<0,0125$ olduğu için ortalama puanlar arasında yedinci sınıf lehine anlamlı bir fark vardır. Beşinci sınıf düzeyinde okumakta olan öğrencilerin problem çözme becerileri yönünden sekizinci sınıf düzeyinde Mann-Whitney $U=51951 ; z=-3,659 ; p$ 
$=0,000<0,0125$ olduğu için ortalama puanlar arasında sekizinci sınıf lehine anlamlı bir fark vardır. Altıncı sınıf düzeyinde okumakta olan öğrencilerin problem çözme becerileri yönünden yedinci sınıf düzeyinde Mann-Whitney $U=83395 ; z=-1,035 ; p$ $=0,301>0,0125$ olduğu için ortalama puanlar arasında anlamlı bir farklılık yoktur. Altıncı sınıf düzeyinde okumakta olan öğrencilerin problem çözme becerileri yönünden sekizinci sınıf düzeyinde Mann-Whitney $U=122163 ; \mathrm{z}=-0,022 ; \mathrm{p}=0,982>0,0125$ olduğu için ortalama puanlar arasında anlamlı bir farklılık yoktur. Yedinci sınıf düzeyinde okumakta olan öğrencilerin problem çözme becerileri yönünden sekizinci sınıf düzeyinde Mann-Whitney $U=84598 ; z=-1,091 ; p=0,275>0,0125$ olduğu için ortalama puanlar arasında anlamlı bir farklılık yoktur.

Tablo 7: Sınıf Düzeyleri Ortalamaları Arasındaki Fark

\begin{tabular}{|c|c|c|c|c|c|c|}
\hline Ölçek & $\begin{array}{l}\text { Sinıf } \\
\text { düzeyi }\end{array}$ & $\begin{array}{l}\text { Ortalama } \\
\text { Siralaması }\end{array}$ & $\begin{array}{l}\text { Mann- } \\
\text { Whitney } \\
\text { U }\end{array}$ & $\begin{array}{l}\text { Wilcoxon } \\
\text { W }\end{array}$ & Z & $\mathrm{p}$ \\
\hline \multirow{12}{*}{$\begin{array}{l}\text { Problem } \\
\text { Çözme } \\
\text { Becerisi }\end{array}$} & 5 & 330,75 & \multirow[t]{2}{*}{51311,500} & \multirow[t]{2}{*}{82686,500} & \multirow[t]{2}{*}{$-3,694$} & \multirow[t]{2}{*}{0,000} \\
\hline & 6 & 392,21 & & & & \\
\hline & 5 & 265,53 & \multirow{2}{*}{35006,5} & \multirow[t]{2}{*}{66381,5} & \multirow[t]{2}{*}{$-4,478$} & \multirow[t]{2}{*}{0,000} \\
\hline & 7 & 330,17 & & & & \\
\hline & 5 & 333,30 & \multirow[t]{2}{*}{51951} & \multirow[t]{2}{*}{83326} & \multirow[t]{2}{*}{$-3,659$} & \multirow[t]{2}{*}{0,000} \\
\hline & 8 & 394,47 & & & & \\
\hline & 6 & 417,10 & \multirow[t]{2}{*}{83395} & \multirow[t]{2}{*}{205213} & \multirow[t]{2}{*}{$-1,035$} & \multirow[t]{2}{*}{0,301} \\
\hline & 7 & 434,73 & & & & \\
\hline & 6 & 495,20 & \multirow[t]{2}{*}{122163} & \multirow[t]{2}{*}{245916} & \multirow[t]{2}{*}{$-0,022$} & \multirow[t]{2}{*}{0,982} \\
\hline & 8 & 494,80 & & & & \\
\hline & 7 & 437,87 & \multirow[t]{2}{*}{84598} & \multirow[t]{2}{*}{208351} & \multirow[t]{2}{*}{$-1,091$} & \multirow[t]{2}{*}{0,275} \\
\hline & 8 & 419,22 & & & & \\
\hline \multirow{12}{*}{$\begin{array}{l}\text { Okuma } \\
\text { Alışkanlığ1 }\end{array}$} & 5 & 432,30 & \multirow[t]{2}{*}{46301} & \multirow[t]{2}{*}{167579} & \multirow[t]{2}{*}{$-5,510$} & \multirow[t]{2}{*}{0,000} \\
\hline & 6 & 340,61 & & & & \\
\hline & 5 & 369,65 & \multirow[t]{2}{*}{27962} & \multirow[t]{2}{*}{91508} & \multirow[t]{2}{*}{$-7,798$} & 0,000 \\
\hline & 7 & 257,04 & & & & \\
\hline & 5 & 493,07 & 32356 & 156109 & - & 0,000 \\
\hline & 8 & 314,10 & & & 10,701 & \\
\hline & 6 & 451,10 & 74490,5 & 138036,5 & $-3,719$ & 0,000 \\
\hline & 7 & 387,74 & & & & \\
\hline & 6 & 560,64 & 89966,5 & 213719,50 & $-7,194$ & 0,000 \\
\hline & 8 & 430,02 & & & & \\
\hline & 7 & 454,90 & 78532 & 202285 & $-2,801$ & 0,005 \\
\hline & 8 & 407,01 & & & & \\
\hline
\end{tabular}


Tablo 7 sınıf düzeylerinde okuma alışkanlığı ortalamaları arasındaki fark incelendiğinde beşinci sınıf düzeyinde okumakta olan öğrencilerin okuma alışkanlığg ortalamaları altıncı sınıf düzeyindeki öğrencilerinin okuma alışkanlığı ortalamalarından (MannWhitney $U=46301 ; \quad z=-5,510 ; \quad p=0,000<0,0125)$, yedinci sinıf düzeyindeki öğrencilerinin okuma alışkanlığı ortalamalarından (Mann-Whitney $U=27962 ; z=-7,798$; $\mathrm{p}=0,000<0,0125)$ ve sekizinci sınıf düzeyinde öğrencilerinin okuma alışkanlığg ortalamalarından (Mann-Whitney $U=32356$; $z=-10,701 ; p=0,000<0,0125$ ) beşinci sınıf lehine anlamlı bir fark vardır. Altıncı sınıf düzeyinde okumakta olan öğrencilerin okuma alışkanlığı yönünden yedinci sınıf düzeyinde Mann-Whitney $U=77490,5$; z=3,$719 ; \mathrm{p}=0,000<0,0125$ olduğu için ortalama puanlar arasında altıncı sınıf lehine anlamlı bir fark vardır. Altıncı sınıf düzeyinde okumakta olan öğrencilerin okuma alışkanlığı yönünden sekizinci sınıf düzeyinde Mann-Whitney $U=89966,5 ; z=-7,194 ; p$ $=0,000<0,0125$ olduğu için ortalama puanlar arasında altıncı sınıf lehine anlamlı bir fark vardır. Yedinci sınıf düzeyinde okumakta olan öğrencilerin okuma alışkanlığı yönünden sekizinci sınıf düzeyinde Mann-Whitney $U=78532 ; \mathrm{z}=-2,801 ; \mathrm{p}=0,005$ $<0,0125$ olduğu için ortalama puanlar arasında yedinci sınıf lehine anlamlı bir fark vardir.

\section{SONUÇ ve TARTIŞMA}

Araştırmada ortaokul öğrencilerinin okuma alışkanlıklarının hangi seviyede olduğu, cinsiyet yönünden okuma alışkanlıkları düzeyleri ve problem çözme becerileri arasında bir fark olup olmadığı, sınıf seviyeleri arasında okuma alışkanlıkları düzeyleri ve problem çözme becerileri arasında fark olup olmadığı ve okuma alışkanlığı düzeyi ile problem çözme becerileri arasındaki ilişki incelenmiştir.

Araştırmanın bulgularına göre öğrencilerin okuma alışkanlıkları, öğrencilerin cinsiyeti yönünden anlamlı bir fark göstermektedir. Kız öğrencilerin okuma alışkanlıkları ortalaması erkek öğrencilerden yüksektir ama istatistiksel olarak bu fark anlamlı değildir. Alanyazında bu sonuca benzer olarak, cinsiyete göre doküman incelemesi yönteminin kullanıldığı araştırma sonucunda, okuma becerisinin cinsiyetler arasında 
ağırlıklı olarak kız öğrencilerin lehine olacak şekilde bir seyir izlediği ortaya çıkmıştır (Arslan, 2013). Araştırmada ortaokul öğrencilerinin kitap okuma tutumları incelenmiş ve elde edilen bulgular neticesinde kız öğrencilerin erkek öğrencilerden daha üst düzeyde okuma tutumuna sahip oldukları görülmüştür (Can, Deniz \& Çeçen, 2016). Araştırmanın bulgularına göre problem çözme becerileri ortaokulda öğrenim gören öğrencilerin cinsiyetleri yönünden anlamlı bir fark göstermemektedir. Benzer şekilde, öğretmenlerin problem çözme becerileri üzerine yapılan başka bir araştırmada, problem çözme algılarının cinsiyet yönünden istatistiksel açıdan anlamlı bir fark göstermediği saptanmıştır (Demirtaş \& Dönmez, 2008). Ortaokul öğretmenlerinin de problem çözme becerileri cinsiyete göre anlamlı bir fark göstermemektedir (İnan, 2015).

Öğrencilerin okuma alışkanlıkları düzeyleri ile problem çözme becerileri arasında pozitif yönlü ve anlamlı bir ilişkisi olduğu görülmektedir. Benzer şekilde Özsoy, Kuruyer ve Çakıroğlu (2015)'da üst düzeyde okuma seviyesine sahip öğrencilerin problem çözme noktasında zorluk yaşamadıklarını, düşük okuma seviyesindeki öğrencilerin ise problem çözmede oldukça zorlandıklarını belirtmişlerdir. Yedinci sınıf öğrencileri ile yürütülmüş başka bir araştırmada öğrencilerin kitap okuma düzeylerinin problem çözme becerileri üzerindeki etkisine bakılmış ve istatistiksel olarak anlamlı bir ilişkiye rastlanmamıştır (Karakılıç \& Arslan, 2019).

Öğrencilerin sınıf seviyelerine göre okuma alışkanlıkları ve problem çözme düzeyleri bazı sınıf seviyelerinde farklılık göstermektedir. Problem çözme becerileri alt sınıf düzeyinde farklılık gösterirken, okuma alışkanlıkları bütün sınıf düzeylerinde farklılık göstermektedir. Okuma alışkanlığı noktasında farkındalık düzeylerinin alt sınıflar lehine bir seyir izlediği görülmektedir.

Sonuç olarak ortaokul öğrencilerinin kitap okuma alışkanlıklarını geliştirmek ve okuduklarını anlama becerisi kazanmalarına katkı sağlamak için farklı öğretim yöntemlerine ve etkinliklere yer verilmelidir. Okul içerisinde ders saatlerinden bazıları okuma saati olarak belirlenmeli ve bu amaca hizmet eden materyaller tasarlanmalıdır. Okuma alışkanlığı kazandırmada ailenin önemi unutulmamalı ve desteği alınmalıdır. 
Yine okul içinde zengin bir kütüphaneye yer verilmeli, okuma kültürü kurum kültürü olarak benimsenmelidir.

$\mathrm{Bu}$ çalışmanın sınırlılıkları ve kısıtlaması ilk olarak sadece ölçekler aracılığıyla veri toplamasıdır. İkinci olarak uzun süreli veri toplanmamış olmasıdır. Öğrencilerden farklı zamanlarda ve konular temelinde veri toplanması önerilmektedir.

$\mathrm{Bu}$ çalışmanın sonuçlarından yola çıkarak araştırmacılara öneriler yapılabilir. Araştırmacılar okuma alışkanlığı becerileri ve problem çözme becerilerini ölçekler ile taradıktan sonra konu bazında da inceleyebilirler. Ortaokul öğrencilerin matematik başarı notları ve Türkçe başarı notları da araştırma kapsamında toplanarak ileri istatistiksel yöntemler kullanılarak öğrencilerin okuma becerileri ve problem çözme becerileri akademik başarı puanlarını ne ölçüde tahmin ediyor incelenebilir. 


\section{KAYNAKLAR}

Akyol, H. (2018). Türkçe ilk okuma yazma öğretimi. Ankara: Pegem Akademi. Arslan, A. (2013). Okuma becerisi ile ilgili makalelerde cinsiyet değişkeni (Reading skills articles on gender variable). Uluslararası Türkçe Edebiyat Kültür Eğitim Dergisi, 2(2), 251-265.

Baykul, Y. \& Fidan, N. (1994). İlköğretimde temel öğrenme ihtiyaçlarının karşılanması. Hacettepe Üniversitesi Egitim Fakltesi Dergisi, 10(10), 7-20.

Bursal, M. (2017). SPSS ile temel veri analizi. Ankara: Anı Yayıncılık.

Büyüköztürk, Ş. (2007). Sosyal bilimler için veri analizi el kitabı. Ankara: Pegem Akademi Yayıncılık.

Büyüköztürk, Ş., Çakmak, E., Akgün, Ş., \& Demirel, F. (2016). Bilimsel araştırma yöntemleri. Ankara: Pegem Akademi.

Can, A. (2016). SPSS ile bilimsel araştırma sürecinde nicel veri analizi. Ankara: Pegem Akademi.

Can, A., Deniz, E., \& Çeçen, M. (2016). Ortaokul öğrencilerinin okuma tutumları (Reading attitudes of middle school students). International Periodical for the Languages, Literature and History of Turkish or Turkic, 11(3), 645-660.

Cohen, J. \& Cohen, P. (1983). Applied multiple regression/correlation analysis for the behavioral sciences. New Jersey: Lavvrence Erlbaum Associates, Publishers.

Demirel, Ö. (2007). Yabancı dil öğretimi. Ankara: Pegem Akademi.

Demirtaş, H. \& Dönmez, B. (2008). Secondary school teachers' perceptions about their problem solving abilities. Inönü Üniversitesi Eğitim Fakültesi, 9(16), 177-198.

Dreher, M. (2002). Motivating teachers to read (Teaching Ideas). The Reading Teacher, 56(4), 338-344.

Guthrie, J. T. \& Wigfield, A. (1999). How motivation fits into a science of reading. Scientific Studies of Reading, 3(3), 199-205.

Güneş, F. (2007). Türkçe öğretimi ve zihinsel yapılandırma. Ankara: Nobel Yayın Dağıtım.

Güney, S. (1998). Davranış bilimleri ve yönetim psikolojisi terimler sözlüğü. Ankara: Ocak Yayınları.

Hughes, H. \& Rodge, P. (2007). The leisure reading habits of urban adolescents. Journal of Adolescent \& Adult Literacy, 51(1), 22-33.

İnan, G. (2015). Ortaokul ögretmenlerinin problem çözme becerileri ve duygusal zeka ilişkisi. Yayımlanmamış yükssek lisans tezi, Sosyal Bilimler Enstitüsü, İstanbul Üniversitesi.

Kalaycı, Ş. (2014). SPSS uygulamalı çok değişkenli istatistik teknikleri. Ankara: Asil Yayıncılık. 
Karakılıç, S. \& Arslan, S. (2019). Kitap okumanın öğrencilerin matematik başarısı ve problem çözme becerisi üzerine etkisi (The impact of book reading on students' problem solving skills and their mathematics success). Turkish Journal of Computer and Mathematics Education, 10(2), 456-475.

Karakuş, İ. (2005). Türkçe, Türk Dili ve Edebiyatı ögretimi. Ankara: Can Reklam Basın Yayın.

Karatay, H. (2014). Okuma eğitimi kuram ve uygulama. Ankara: Pegem Akademi.

Kavcar, C. \& Oğuzkan, F. (1998). Türkçe öğretimi. Ankara: Engin Yayınevi.

Marshall, J. (1994). Ana dili ve yazım öğretimi. (C. Kübebi, Çev.) İstanbul: Çağdaş Yayınlar1.

Nakip, M. \& Yaraş, E. (2016). SPSS uygulamala pazarlamada araştırma teknikleri. Ankara: Seçkin Akademik ve Mesleki Yayınlar.

NCTM (1988). NCTM curriculum and evaluation standards for school mathematics: responses from the research community. Journal for Research in Mathematics Education, 19(4), 338-344.

Özsoy, G., Kuruyer, H., \& Çakıroğlu, A. (2015). Evaluation of students' mathematical problem solving skills in relation to their reading levels. International Electronic Journal of Elementary Education, 8(1), 113-132.

Pallant, J. (2016). SPSS survival manual (Çev. S. Balcı, B. Ahi). Ankara: Anı Yayıncilik.

Polya, G. (2017). Nasıl çözmeli? matematiksel yönteme yeni bir bakış. (Çev. B. S. Soyer). Ankara: TÜBİTAK Popüler Bilim Kitapları.

Robson, C. (2017). Bilimsel araştırma yöntemleri gerçek dünya araştırmaları (Çev. Ş. Çınkır, N. Demirkasımoğlu). Ankara: Anı Yayıncılık.

Samuels, S. \& Farstrup, A. E. (2006). What research has to say about fluency instruction. Newark: International Reading Association.

Serin, O., Serin, N., \& Saygılı, G. (2010). İlköğretim düzeyindeki çocuklar için problem çözme envanteri'nin (ÇPÇE) geliştirilmesi (Developing problem solving inventory for children at the level of primary education (PSIC)). Ilkögretim Online, 9(2), 446-458.

Tok, M., Küçük, B., \& Kırmacı, M. (2015). Ortaokul kitap okuma alışkanlığı ölçeği: geçerlik güvenirlik çalışması (Secondary school reading habit scale: validity and reliability study). Eğitimde Kuram ve Uygulama, 11(2), 694-716.

Umay, A. (2002). Öteki matematik (The Other mathematics). Hacettepe Üniversitesi Eğitim Fakültesi Dergisi, 23, 275-281.

Ünalan, Ş. (2006). Türkçe öğretimi. Ankara: Nobel Yayın Dağıtım.

Yılmaz, M. (2008). Kelime tekrar tekniğinin akıcı okuma becerilerini geliştirmeye etkisi (The effect of word drill technique on improving fluently reading of skills). Türk Ĕ̈itim Bilimleri Dergisi, 6(2), 323-350. 


\section{ORCID}

Sevim SEVGi ${ }^{(1)}$ https://orcid.org/0000-0002-6611-5543

Mustafa KARAKAYA https://orcid.org/0000-0002-9263-3213 


\section{SUMMARY}

In the study, the level of middle-school students' reading habits, whether there is a mean difference between their reading ability and problem-solving skills in terms of gender, whether there is a mean difference between the grade levels of reading abilities and problem-solving skills, and the relationship between the reading ability and problem-solving skills were analyzed. The Middle School Reading Ability Scale developed by Tok, Küçük, and Kırmacı (2015), was used to determine reading ability. Cronbach's Alpha value was found to be 0.863. For problem-solving skills, the problem-solving inventory for primary school children developed by Serin, Serin, and Saygll (2010) was used. The Cronbach Alpha reliability coefficient was found to be 0.80. The data collected from the middle-school reading ability scale and the problem-solving inventory were analyzed with SPSS. In this context, descriptive statistics, normality analysis, the KruskalWallis, correlation analysis, and the Mann-Whitney $U$ test were conducted. The KolmogorovSmirnov test result $D(1595)=0.052, p=0.000<0.05$ in the reading ability scale; and problemsolving inventory test result $D(1595)=0.046, p=0.000<0.05$ did not provide a normal distribution at 0.05 significance levels.

The Kolmogorov-Smirnov test result did not show a normal distribution according to gender. Problem solving inventory for male students was $D(1595)=0.53, p=0.000<0.05$, and for female students was $D(1595)=0.49, p=0.000<0.05$. Reading ability scale male students was $D$ $(1595)=0.42, p=0.000<0.05$, and for female students was $D(1595)=0.062, p=0.000<0.05$. Problem-solving skills were Mann-Whitney $U=316278, z=-0169, p=0.866$, Wilcoxon $W=$ 620088, and there was no statistically significant mean difference between male and female students in terms of problem-solving skills. Reading ability was Mann-Whitney $U=248039, z=-$ 7,594; Wilcoxon $W=581375, p=0.000$. The statistically significant mean difference in reading ability by gender-favored female students was shown. It was statistically significant at the 0.01 level between problem-solving skill and reading ability $(r=0.124, p=0.000<0.01)$. There was a significant positive relationship between students' reading ability and problem-solving skills. Problem-solving and reading ability scores did not provide the normal distribution assumption in any subgroup since the Kolmogorov-Smirnov normality test results were $p<0.05$. There was a significant mean difference of the reading ability total scores of the students attending middle school at the level of grade level $\left[X^{2}(3,1595)=102.789, p=0.000<0.05\right]$,. Similarly, there was a significant mean difference between the groups in the problem-solving skills total scores of the students who attend middle school, their mean of the grade levels $\left[X^{2}(3,1595)=12.643, p=\right.$ $0.000<0.05]$. There was a significant mean difference between at least two of the four grade levels. According to the study's findings, the students' reading ability showed a statistically significant mean difference in terms of the gender of the students. Although not statistically significant, the mean reading ability of female students was higher than male students. Similar results were found in the literature. As a result of the research using the document analysis method related to the gender, it was revealed that the reading skills were predominantly in favor of female students across genders (Arslan, 2013). Middle-school students' reading attitudes were analyzed, and because of the findings, female students had a higher reading attitude than male students (Can, Deniz, \& Çeçen, 2016). According to the study's findings, problem-solving skills 
did not show a statistically significant mean difference in terms of the gender of the students studying at middle school.

Similarly, in another study conducted on teachers' problem-solving skills, there was no statistically significant mean difference in problem-solving perceptions in terms of gender (Demirtaş \& Dönmez, 2008). Middle-school teachers' problem-solving skills did not show a statistically significant mean difference according to gender (Inan, 2015). There was a positive and significant relationship between students' reading ability and problem-solving skills. Similarly, Özsoy, Kuruyer, and Çakıroğlu (2015) stated in their research that students with high reading level did not have difficulty solving problems. In contrast, students with low reading levels had trouble solving problems. In another study conducted with seventh-grade students, no statistically significant relationship was found when the effect of students' reading levels on their problem-solving skills was examined (Karakılıç \& Arslan, 2019). Students' reading ability and problem-solving levels differ at some grade levels according to their grade levels. 
Ek 1. Etik Kurul Onay Belgesi

BAŞVURU NO: 157

ERCIYES ÜNIVERSITESI SOSYAL VE BEȘERI BILIMLER ETIK KURULU PROJE ONAY FORMU

\begin{tabular}{|c|c|}
\hline Projenin Adı & $\begin{array}{l}\text { "Ortaokul Ögrencilerinin Okuma Alışkanlığıyla Problem Çözme } \\
\text { Becerisinin Incelenmesi" }\end{array}$ \\
\hline Projenin Niteliği & Diğer/Makale \\
\hline $\begin{array}{l}\text { Proje } \\
\text { Araştırmacıları }\end{array}$ & $\begin{array}{l}\text { Mustafa KARAKAYA } \quad \text { (Sorumlu Araştırmacı) } \\
\text { Dr. Öğr. Üyesi SEVIM SEVGI (Danışman) }\end{array}$ \\
\hline $\begin{array}{l}\text { Sorumlu } \\
\text { Araştırmacının } \\
\text { Haberleșme } \\
\text { Bilgileri }\end{array}$ & $\begin{array}{l}\text { Mustafa KARAKAYA } \quad \text { (Sorumlu Araştırmacı) } \\
\text { Dr. Öğr. Üyesi SEVIM SEVGi (Danışman) } \\
\text { Ug̃urevler M. 19. Cadde No:79 Tekin Plus A. Kat:5 Daire: 14 Kocasinan / } \\
\text { Kayseri } \\
\text { E-posta adresi: mustafakarakaya008@gmail.com }\end{array}$ \\
\hline
\end{tabular}

Etik Kurulumuza başvuran Mustafa KARAKAYA'nı “Ortaokul Öğrencilerinin Okuma Alışkanlığıyla Problem Çözme Becerisinin Íncelenmesi” adlı Çalışması değerlendirilerek aşağıdaki sonuca ulaşılmıştır.

Proje etik açıdan uygun bulunmuștur.

Projenin etik açıdan geliştirilmesi

gerekmektedir.

Proje etik açıdan uygun bulunmamıștır.

$27 / 10 / 2020$

\begin{tabular}{|l|l|l|}
\hline Etik Kurul Başkanı & Prof. Dr. Atabey KILIÇ \\
\hline $\begin{array}{l}\text { Etik Kurul Başkan } \\
\text { Yrd. (Raportör) }\end{array}$ & Prof. Dr. Kasım KARAMAN \\
\hline Üye & Prof. Dr. Celal YILDIZ & Prof. Dr. Mustafa KARAGÖZ \\
\hline Ûye & Prof. Dr. Hakan AYDIN & Prof. Dr. Mikail AKBULUT \\
\hline Üye & Prof. Dr. Handan ZINCIR & Doç. Dr. Ahmet HASKOSE \\
\hline Ûye & Doç. Dr. Burak ADIGUZEL & \\
\hline Üye & &
\end{tabular}


